\title{
PENGARUH FAKTOR-FAKTOR PROFESIONAL, PERSONAL, LINGKUNGAN, TEKNOLOGI INFORMASI DAN KEPUASAN TERHADAP PRESTASI MAHASISWA MELALUI PENGGUNAAN $E$ - LEARNING BERKELANJUTAN SEBAGAI VARIABEL MEDIASI
}

\author{
Metodius Manek $^{1 *}$, Justine Tanuwijaya ${ }^{2}$ \\ ${ }^{1}$ Mahasiswa Magister Manajemen Fakultas Ekonomi dan Bisnis Universitas Trisakti, Jakarta, Indonesia \\ Email: metodiusamanek@gmail.com \\ ${ }^{2}$ Dosen Fakultas Ekonomi dan Bisnis Universitas Trisakti, Jakarta, Indonesia \\ Email:justine@trisakti.ac.id \\ *penulis korespondensi
}

Masuk : 14-04-2021, revisi: 08-10-2021, diterima untuk diterbitkan : 10-10-2021

\begin{abstract}
ABSTRAK
Penggunaan e-learning berkelanjutan sangat urgen diciptakan dan dikembangkan di setiap lembaga pendidikan formal karena dapat memutus rantai penyebaran covid-19 sekaligus meningkatkan prestasi peserta didik pada era normal baru ini. Dengan demikian perlu diketahui faktor-faktor determinan yang dapat mewujudkan penggunaan e-learning berkelanjutan. Tujuan penelitian ini untuk membuktikan secara empiris pengaruh faktor-faktor profesional, personal, lingkungan, teknologi informasi dan kepuasan terhadap prestasi mahasiswa di Fakultas Ekonomi dan Bisnis Universitas Trisakti melalui penggunaan e-learning berkelanjutan sebagai variabel mediasi. Metode yang digunakan adalah metode kuantitatif melalui penyebaran 50 item kuesioner berskala Likert 5 poin via google form kepada 279 responden. Data penelitian dianalisis dengan analisis deskriptif dan pengujian hipotesis dengan menggunakan SEM. Hasil penelitian membuktikan bahwa faktor determinan yang paling signifikan mempengaruhi penggunaan $e$-learning berkelanjutan adalah faktor-faktor personal. Terbukti secara empiris juga bahwa penggunaan $e$-learning berkelanjutan mempengaruhi prestasi mahasiswa, sehingga perlu diberi perhatian serius pada faktor-faktor personal. Hasil penelitian diharapkan berkontribusi pada pihak manajemen FEB untuk menciptkan dan mengembangkan e-learning yang mendukung efektivitas dan prestasi mahasiswa. Saran untuk penelitian selanjutnya perlu memberikan pemahaman tentang e-learning sebelum membuat penelitian dengan tema yang sama atau membuat penelitian tentang tingkat literasi terhadap cakupan makna e-learning berkelanjutan.
\end{abstract}

Kata Kunci: e-learning berkelanjutan, faktor-faktor penentu, prestasi mahasiswa

\begin{abstract}
Sustainable use of e-learning is very urgent created and developed in any formal education institutions because it can break the chain of covid-19 while improving the achievement of students in this new normal era. Therefore, it takes determinant factors that can realize the use of sustainable e-learning. The purpose of this study is to empirically prove the influence of professional, personal, environmental, information technology and satisfaction factors on student achievement at the Faculty of Economics and Business, Trisakti University through the use of sustainable e-learning as a mediating variable. The method used is quantitative method through the deployment of 50 item 5-point Likert scale questionnaire via google form to 279 respondents. The research data were analyzed using descriptive analysis and hypothesis testing using SEM. The results of this study prove that the most significant determinant factors affecting the use of sustainable e-learning are personal factors. It is also empirically proven that the use of sustainable elearning affects student achievement. Therefore, it is necessary to pay serious attention to personal factors. This finding is expected can give contribution for management of Faculty of Economics and Business for creating and developing e-learning which supports effectiveness and student performance. Therefore, the suggestion is that further research needs to provide an understanding of e-learning before making research with the same theme or making research on the level of literacy on the scope of meaning of sustainable e-learning.
\end{abstract}

Keywords: sustainable e-learning, determinant factors, student performance

\section{PENDAHULUAN}

Pandemi Covid-19 membawa perubahan yang sangat cepat dan tiba-tiba di dalam sistem pendidikan (Moawad, 2020). Dampaknya terhadap keseluruhan institusi pendidikan tinggi tidak 
terhindarkan. Penutupan universitas tanpa direncanakan pun terjadi di mana-mana (Tsekea and Chigwada, 2020). Hampir semua elemen di dalam lembaga pendidikan tinggi merasa seperti mengalami dentuman besar yang mengagetkan dan mendapati diri teralienasi dari kehidupan harian, sehingga bingung tak tahu arah serta merasa berada dalam ketidakpastian. Hadirnya covid19 menempatkan lembaga pendidikan tinggi pada pilihan dilematis. Di satu sisi, jika tetap memaksakan diri untuk melakukan proses pembelajaran secara tatap muka langsung, risiko penyebaran covid-19 tak terhindarkan. Di sisi lain, jika tetap diam di rumah saja, pembelajaran tidak terjadi sehingga nasib semua elemen di dalam lembaga pendidikan tinggi dipertaruhkan. Akhirnya, secara global dirasakan bahwa solusi yang urgen dilakukan adalah pembelajaran hanya boleh dilakukan secara online (Almekhlafy, 2020). Di Indonesia pun terjadi hal yang sama (Fatoni et al., 2020). Pembelajaran berbasis elektronik (e-learning) yang sebelumnya menjadi alternatif saja, kini menjadi satu-satunya pilihan agar proses pembelajaran tetap berlangsung dari rumah masing-masing sekaligus menjadi cara bersama untuk memutus rantai penyebaran covid-19.

Covid-19 "seolah-olah telah membantu merealisasikan" evolusi dalam dunia pendidikan. Hal ini terlihat jelas dalam sejarah pembenahan sistem pembelajaran global. Sudah sejak Pertengahan Abad XX, para ahli di dunia pendidikan mengindikasikan bahwa ada yang salah dengan sistem pembelajaran (Knowles, 1980). Oleh karena itu, sistem pembelajaran harus dibenahi. Telah disadari sejak lama bahwa hal terpenting dalam sistem pembelajaran, baik bagi anak-anak maupun orang dewasa, adalah merancang bagaimana cara belajar. Dalam hal ini, proses pembelajaran membutuhkan keterampilan untuk belajar mandiri. Menurut Knowles (1980), pendidikan tidak lagi bisa didefinisikan sebagai sebuah proses transmisi apa yang diketahui, tetapi harus didefinisikan sebagai sebuah proses penyelidikan berkelanjutan seumur hidup. Oleh karena itu, model pedagogi yang berpusat pada guru harus digantikan dengan andragogi yang berpusat pada peserta didik. Dalam perkembangannya, Hase and Kenyon (2001) menemukan bahwa andragogi pun tidak bisa dipertahankan lagi, sehingga harus beralih menjadi heutagogi, yaitu pembelajaran yang ditentukan oleh diri sendiri. Temuan model baru heutagogi ini selanjutnya dikembangkan bersama Blaschke sebagai perluasan dari andragogi atau pembelajaran mandiri temuan Knowles pada tahun 1970 (Blaschke, 2012).

Dalam riset Blaschke and Hase (2016) dinyatakan bahwa kita berada di zaman emansipasi pengetahuan dan keterampilan. Tidak ada hambatan untuk mengetahui, dan keterampilan yang dibutuhkan untuk menjadi seorang pelajar yang efektif dalam abad XXI ini telah berubah secara dramatis, yaitu peserta didik telah berubah dari penerima pasif menjadi seorang analis dan pembuat sintesis. Alasan utamanya adalah telah disadari oleh para praktisi dan peneliti di dunia pendidikan bahwa struktur kognisi manusia memungkinkan setiap orang untuk belajar secara mandiri, bahkan bisa menentukan sendiri apa yang akan dipelajari dan bagaimana cara mempelajarinya serta hasil apa yang diharapkan dan bagaimana mengevaluasi proses pembelajaran tersebut (Hase and Kenyon, 2001). Oleh karena itu, desain sistem pembelajaran tidak cukup hanya mendorong peserta didik untuk memenuhi standar kompetensi pembelajaran tertentu, tetapi juga harus diciptakan ruang kebebasan untuk mengembangkan kapabilitas peserta didik agar mampu menjadi pelajar seumur hidup, baik selama berada di bangku perkuliahan maupun ketika sudah berada di tempat kerja kelak (Blaschke, 2012). Inilah intisari dari pendekatan pembelajaran heutagogi, yaitu peserta didik mandiri dalam seluruh proses pembelajarannya (Hase and Kenyon, 2000; Blaschke, 2012; Blaschke and Hase, 2016). Dalam konteks pandemi covid-19, model pembelajaran heutagogi yang didesain dengan sistem pembelajaran berbasis elektronik (e-learning) menjadi jawaban yang tepat. Dengan model pembelajaran heutagogi, setiap peserta didik akan tetap berada di rumah masingmasing dan bebas menetukan sistem pembelajaran masing-masing. Ja'ashan (2015) menyatakan bahwa sudah sejak lama penggunaan teknologi dalam dunia pendidikan menjadi kebutuhan dan 
tak terelakkan. Menurut Tsekea and Chigwada (2020), munculnya pandemi covid-19 memperlihatkan penggunaan teknologi di dunia pendidikan tinggi telah membawa beberapa perubahan radikal di dalam dinamika pembelajaran.

Adanya kontribusi positif dalam penggunaan sistem e-learning sebagai solusi aktual atas kesulitan pembelajaran tatap muka langsung karena pandemi covid-19 merupakan alasan utama penelitian ini dilakukan. Fokus penelitian ini adalah menganalisis faktor apa saja yang seharusnya ada agar penggunaan e-learning terjadi secara berkelanjutan. Hal ini tentu saja akan berkotribusi untuk memutus rantai penyebaran covid-19. Selain itu, penggunaan e-learning berkelanjutan sangat sesuai dengan temuan model pendekatan baru dalam sistem pendidikan, yaitu heutagogi (Hase and Kenyon, 2000; Blaschke 2012; Blaschke and Hase, 2016). Penerapan sistem e-learning akan membiasakan peserta didik menjadi pribadi yang mandiri dalam menentukan sistem pembelajarannya sendiri baik selama masih di bangku kuliah maupun ketika sudah terjun ke tempat kerja mereka. Dengan demikian, pendekatan heutagogi ini sekaligus menjadi landasan teoretis diterapkan sistem pembelajaran e-learning secara berkelanjutan yang bertujuan meningkatkan prestasi mahasiswa. Untuk mencapai tujuan tersebut, dibutuhkan faktor-faktor penentu yang memungkinkan penggunaan $e$-learning berkelanjutan terjadi. Oleh karena itu, tujuan penelitian ini adalah menganalisis pengaruh faktor-faktor profesional, personal, lingkungan, teknologi informasi dan kepuasan terhadap prestasi mahasiswa melalui penggunaan e-learning berkelanjutan sebagai variabel mediasi.

\section{TINJAUAN TEORI DAN PENGEMBANGAN HIPOTESIS}

\section{Faktor-faktor Profesional dan Penggunaan E-learning Berkelanjutan}

Faktor-faktor profesional terdiri dari dukungan fakultas, dukungan manajemen, dan dukungan pembelajaran (Kapo et al., 2020). Di dalamnya, faktor determinan paling signifikan adalah para pengajar. Menurut Tayyaba (2012), perilaku pengajar sangat menentukan prestasi peserta didik, baik di pedesaan maupun perkotaan. Bantuan (Moradi et al., 2020) dan kecerdasan emosional (Alam and Ahmad, 2018) pengajar menjadi syarat mutlak perubahan perilaku peserta didik. Jadi, kompetensi kepribadian seorang pengajar memberikan kontribusi positif bagi motivasi dan kedisiplinan studi peserta didik (Kheruniah, 2013). Selain itu, dukungan fakultas/universitas dibutuhkan untuk mampu merangsang niat wirausaha peserta didik dan mengontrol perilakunya (Trivedi, 2016) sehingga berorientasi pada kemandirian (Shi et al., 2019) Buktinya, peserta didik dan akademisi perempuan yang dituntut untuk bekerja sekaligus membagi peran sebagai ibu rumah tangga (Achour et al., 2017) mampu berprestasi dan berwirausaha bila ada dukungan dari universitas meskipun dalam budaya tertentu mereka dipandang rendah (Sidratulmunthah et al., 2018). Selain itu, dukungan manajemen dan atasan juga dibutuhkan oleh peserta didik ketika mengadopsi teknologi baru demi sebuah inovasi (Hsu et al., 2019). Hal ini lebih sering dialami oleh orang yang lebih suka pada gagasan para profesional (Boros and van Gorp, 2017). Semakin tinggi dukungan dari para profesional, niat untuk terus-menerus menggunakan e-learning pun semakin tinggi. Dengan demikian, hipotesis yang dikembangkan sebagai berikut:

H1: Terdapat pengaruh positif faktor-faktor profesional terhadap penggunaan e-learning berkelanjutan.

\section{Faktor-faktor Personal dan Penggunaan E-learning Berkelanjutan}

Faktor-faktor personal terdiri dari harapan kinerja, keunggulan relatif, kesesuaian, dan sikap pengguna terhadap e-learning (Kapo et al., 2020). Harapan kinerja ini didefinisikan sebagai seberapa besar individu percaya bahwa penggunaan sistem tertentu akan membantunya mencapai kinerja yang diharapkan (Venkatesh et al., 2003; Pynoo et al., 2011). Harapan kinerja ini secara konsisten menjadi prediktor terkuat terhadap intensi perilaku individu dalam menggunakan 
teknologi tertentu (Venkatesh et al., 2003; Venkatesh et al., 2012). Hasil penelitian empiris Taiwo and Downe (2013) terhadap model UTAUT (The Unified Theory of Acceptance and Use of Technology) membuktikan hal yang sama, yaitu harapan kinerja dan intensi perilaku memiliki hubungan yang kuat. Semakin besar penggunaan e-learning tertentu memenuhi harapan dari peserta didik, semakin besar pula keinginannya untuk menggunakannya secara konsisten.

Faktor personal lainnya adalah keunggulan relatif dan kesesuaian atau kecocokan (Kapo et al., 2020). Orisinalitas kedua konsep ini terdapat pada konsep difusi inovasi Rogers (1983). Menurut Rogers, keunggulan relatif merujuk pada sejauh mana sebuah inovasi teknologi dianggap lebih baik daripada yang digunakan sebelumnya, sedangkan kesesuaian atau kecocokan adalah sejauh mana inovasi tersebut dianggap konsisten dengan nilai yang ada, pengalaman masa lalu, dan kebutuhan potensial dari para pengguna (Rogers, 1983). Dalam konteks penelitian ini, jika desain e-learning tertentu memberikan manfaat yang unik bagi peserta didik dan cocok dengannya, maka mereka memutuskan untuk menggunakannya berulang kali. Oleh karena itu, faktor keunggulan relatif dan kesesuaian terkait dengan sikap pengguna terhadap e-learning karena pengaruhnya sangat signifikan pada penerimaan dan konsistensi penggunaan e-learning tertentu (Al-Harbi, 2011; Elfaki et al., 2019). Hossain et al. (2020) mendefinisikan sikap sebagai respon pengguna terhadap adaptasi teknologi dalam kehidupan. Sikap pengguna merujuk pada sudut pandang pribadi, pola pikir, dan kepercayaan pada pelayanan yang telah dan sedang diterima. Semakin besar unsur-unsur personal ini mengonstruksikan sikap yang positif, semakin besar juga pengaruhnya pada penerimaan dan konsistensi peserta didik terhadap e-learning yang ditawarkan. Dengan demikian, hipotesis dalam penelitian ini dirumuskan sebagai berikut:

$\mathbf{H}_{2}$ : Terdapat pengaruh positif faktor-faktor personal terhadap penggunaan e-learning berkelanjutan.

\section{Faktor-faktor Lingkungan dan Penggunaan E-learning Berkelanjutan}

Ada tiga faktor lingkungan atau sosial yang mempengaruhi penggunaan e-learning berkelanjutan, yaitu rekan kuliah, keluarga dan teman serta dukungan lainnya (Kapo et al., 2020). Faktor sosial merujuk pada sejauh mana seseorang menunjukkan perilaku tertentu karena diminta atau dimotivasi oleh orang lain yang dipercayainya (Hernandez et al., 2011), misalnya teman (Lee, 2010), rekan kuliah (Lai and Chen, 2011), keluarga (Zainuddin et al., 2020), dan siapa saja yang berarti baginya (Zuiderwijk et al., 2015), terutama dalam menghadapi pandemi covid-19 (Doucet et al., 2020). Ketika seseorang menemukan bahwa orang-orang di sekitarnya menggunakan sebuah sarana dalam konteks e-learning dan merasakan manfaatnya, orang tersebut akan lebih ingin untuk menggunakannya (Hernandez et al., 2011). Dengan demikian, faktor-faktor lingkungan sangat menentukan pilihan peserta didik untuk mengunakan e-learning tertentu secara berkelanjutan (Diño and de Guzman, 2015). Oleh karena itu, penelitian ini bermaksud untuk menganalisis pengaruh faktor-faktor lingkungan terhadap penggunaan e-learning berkelanjutan. Hipotesis yang dikembangkan sebagai berikut:

H3: Terdapat pengaruh positif faktor-faktor lingkungan terhadap penggunaan e-learning berkelanjutan.

\section{Faktor Teknologi Informasi dan Penggunaan E-learning Berkelanjutan}

Salah satu model teori yang mendasari pengaruh faktor teknologi informasi terhadap penggunaan e-learning berkelanjutan adalah UTAUT. Teori ini dirumuskan oleh Venkatesh et al. (2003), mencakup unsur harapan kinerja, harapan usaha, pengaruh sosial dan kondisi fasilitas (Venkatesh et al., 2003), dan kemudian dikembangkan lagi oleh Venkatesh et al. (2012) dengan unsur menambahkan motivasi hedonis, nilai harga dan kebiasaan (Venkatesh et al., 2012; Lee et al., 2010). Semua unsur dalam UTAUT tersebut terkait dengan manfaat yang dirasakan, kemudahan 
dalam menggunakan, dan ketersediaan teknologi informasi baru (Diño et al. 2015). Oleh karena itu, dimensi-dimensi dalam model UTAUT tersebut erat kaitannya dengan faktor teknologi informasi di dalam penelitian ini. Liu and Liu (2020) menyatakan bahwa preferensi peserta didik dalam memilih dan menggunakan secara terus-menerus teknologi informasi baru disebabkan oleh adanya kemudahan dalam menggunakannya serta bermanfaat bagi mereka. Hal ini tentu saja terkait erat dengan pemahaman pribadi pengguna terhadap e-learning karena sangat menentukan penerimaan dan keberlanjutan penggunaannya (Koehler and Mishra, 2013; Salim et al., 2020), baik sebagai peserta didik maupun pengajar (Tosuntaş et al., 2015). Jadi, faktor teknologi informasi ini terkait dengan pemahaman, kemudahan dan manfaatnya bagi pengguna dalam menggunakan e-learning tertentu. Jika teknologi informasi yang digunakan dalam e-learning tersedia dan mudah dipahami, sehingga memberi manfaat bagi peserta didik, mereka akan memutuskan untuk terus menggunakannya. Oleh karena itu, penelitian ini bermaksud menganalisis pengaruh faktor teknologi informasi terhadap penggunaan $e$-learning berkelanjutan, sehingga hipotesisnya:

H4: Terdapat pengaruh positif faktor teknologi terhadap penggunaan e-learning berkelanjutan.

\section{Faktor Kepuasan dan Penggunaan E-learning Berkelanjutan}

Faktor kepuasan memiliki pengaruh paling signifikan terhadap niat peserta didik untuk menggunakan e-learning secara berkelanjutan (Lee, 2010). Kepuasan mengacu pada sejauh mana seseorang senang atau puas dengan suatu produk, layanan atau artefak teknologi informasi tertentu setelah mendapatkan pengalaman langsung menggunakannya (Hossain et al., 2020). Dalam hal ini, kepuasan pengguna terkait erat dengan kualitas sistem teknologi informasinya, kualitas $e$ service dan kualitas e-information yang secara positif berkontribusi terhadap e-learning peserta didik (Shehzadi et al., 2020). Ketiga hal tersebut merupakan determinan kepuasan pengguna sekaligus yang mendorongnya untuk berulang kali menggunakan e-learning tertentu bahkan menyebarkannya agar orang lain menggunakannya juga (Chang, 2013), terutama selama masa pandemi covid-19 (Fatoni et al., 2020). Penelitian Elfaki et al. (2019) membuktikan secara empiris bahwa peserta didik yang menggunakan $e$-learning merasa lebih puas menerima hasil studi mereka karena e-learning yang digunakan mampu membantu mereka lebih berprestasi daripada mereka yang hanya menggunakan pembelajaran konvensional. Dalam teori keberlanjutan teknologi (technology continuance theory), dinyatakan bahwa ada hubungan positif di antara manfaat yang dirasakan, kepuasan yang diterima pengguna dan sikap serta niatnya untuk terus-menerus menggunakan sebuah teknologi informasi (Foroughi et al., 2019). Hipotesis yang diajukan yaitu: H5: Terdapat pengaruh positif kepuasan terhadap penggunaan e-learning berkelanjutan.

\section{Penggunaan E-learning Berkelanjutan dan Prestasi Mahasiswa}

Suryaman et al. (2020) mengemukakan beberapa kendala yang dialami oleh peserta didik, para pengajar, dan orang tua dalam pembelajaran daring selama pandemi covid-19. Oleh karena itu, harus didesain proses pembelajaran secara akademis dan sosio-emosional agar menciptakan pembelajaran yang lebih baik, efektif, dan menarik. Sebagai tawaran solusi, Abumandour (2020) mengatakan bahwa e-learning dapat menjadi sebuah metode baru dan menjanjikan bagi sistem pengajaran dan pembelajaran yang relevan. Salah satu aspek dari sistem e-learning adalah sistem pembelajaran online (dalam jaringan/daring). Dhawan (2020) mengatakan bahwa pembelajaran daring dapat dipahami sebagai sarana untuk menciptakan dan mengembangkan proses belajarmengajar lebih berpusat pada peserta didik, lebih inovatif dan fleksibel. Menurut Yilmaz et al. (2013), lingkungan digital ini memungkinkan beragam sumber informasi, sejarah dan nilai kultural tersedia pada satu platform yang sama. Jika pada pembelajaran tatap muka langsung informasi dan pengetahuan hanya tersedia pada satu waktu aktual, pembelajaran berbasis elektronik justru menyediakannya kapanpun dan di manapun sejauh memungkinkan untuk diakses. Oleh karena itu, 
sistem e-learning berkelanjutan membiasakan orang belajar tanpa batas, sehingga menjadi profesional dan berprestasi karena selalu memiliki tambahan informasi dan pengetahuan baru kalau mau menggunakannya.

Sederhananya, e-learning didefinisikan sebagai proses pembelajaran yang secara khusus disampaikan dari satu tempat ke tempat lain melalui teknologi informasi dan komunikasi berbasis internet untuk meningkatkan atau mendukung pembelajaran (Oye et al., 2011; Elfaki et al., 2019). Dengan bantuan internet, peserta didik memanfaatkan teknologi jaringan untuk menciptakan, membantu perkembangan, mengirim dan memfasilitasi pembelajaran kapanpun dan di manapun (Oye et al., 2011). Dengan pendekatan ini, peserta didik diberdayakan sehingga guru/pelatih/tutor tidak lagi menjadi penjaga gerbang pengetahuan, tetapi lebih berperan sebagai fasilitator. Desain e-learning berkelanjutan ini mampu merealisasikan dan melanggengkan heutagogi, yaitu pendekatan yang menempatkan peserta didik sebagai partisipan yang aktif sekaligus pusat dalam proses pembelajarannya (Nikolovska et al., 2020).

Hossain et al. (2020) mendefinisikan intensi berkelanjutan (continuous intention) sebagai perilaku persisten dari seorang pengguna untuk menggunakan suatu layanan secara berulang-ulang. Hal ini merujuk pada penggunaan sebuah teknologi informasi secara terus-menerus untuk jangka panjang setelah penerimaan inisial mereka (Bhattacherejee, 2001; Bhattacherejee and Barfar, 2011). Niat peserta didik untuk menggunakan sistem e-learning secara keberlanjutan menunjukkan sejauh mana individu tersebut mau untuk menggunakan sistem e-learning pada waktu mendatang dan merekomendasikan sistem tersebut kepada orang lain (Chang, 2013). Melalui partisipasi peserta didik di dalam sistem pembelajaran online atau e-learning berkelanjutan, prestasi mahasiswa pun terwujud (Elfaki et al., 2019). Jadi hipotesis yang dikembangkan sebagai berikut:

H6: Terdapat pengaruh positif penggunaan e-learning berkelanjutan terhadap prestasi mahasiswa.

Keenam hipotesis ini digambarkan hubungan pengaruhnya sebagai berikut.

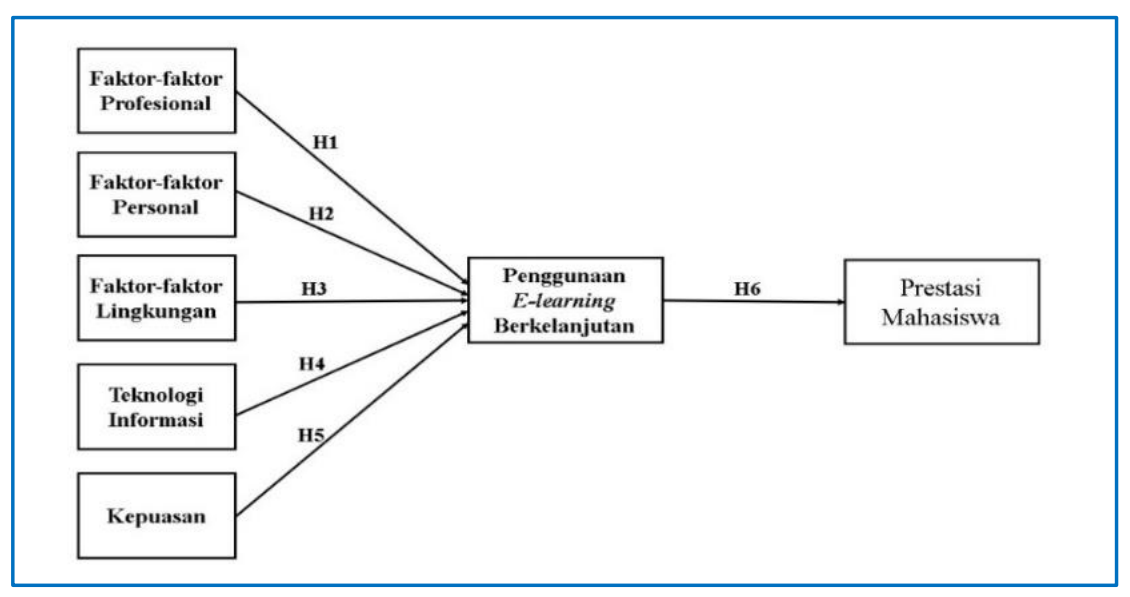

Gambar 1. Kerangka konseptual penelitian

\section{METODE PENELITIAN}

Studi empiris tentang pengaruh variabel-variabel penelitian ini dilakukan dengan metode kuantitatif. Data penelitian diseleksi secara acak sederhana (Levin \& Robin, 1991; Lind et al., 2014; Sugiyono, 2017) dan tanpa dibatasi (Sekaran, 2003; Sekaran \& Bougie, 2016), yaitu dengan menyebarkan kuesioner berisi 50 item pernyataan via google form kepada para mahasiswa Fakultas Ekonomi dan Bisnis Universitas Trisakti dengan jenjang pendidikan mulai dari Diploma Tiga (D3) sampai Strata Tiga (S3). Data profil responden dalam penelitian ini diklasifikasikan 
berdasarkan gender, jenjang pendidikan sekarang, usia, status perkawinan, pekerjaan saat ini, dan masa studi hingga saat ini. Jumlah mahasiswa yang mengisi kuesioner sebanyak 279 responden dan seluruh tanggapannya digunakan untuk pengolahan data penelitian ini, terdiri dari 113 lakilaki dan 116 perempuan. Responden dengan jenjang pendidikan D3 berjumlah 47 mahasiswa, S1 125 mahasiswa, S2 87 mahasiswa, dan S3 20 mahasiswa. Dari total 169 responden tersebut, yang berusia maksimal 20 tahun sebanyak 53 responden, kisaran usia 21-30 tahun sebanyak 165 responden, 31-40 berjumlah 28 responden, dan usia di atas 40 tahun berjumlah 29 responden. Sebagian besar responden belum menikah, yaitu sebesar 217 responden, dan sisanya 62 responden sudah menikah. Menariknya, lebih banyak responden berstatus sudah bekerja, yaitu sebesar 145 responden, artinya mereka sedang bekerja dan kuliah pada waktu yang sama. Selain itu, ada 134 responden yang belum bekerja atau sekarang sedang tidak bekerja karena ingin fokus dengan perkuliahan. Responden pada saat penelitian ini dilakukan sedang berada dalam masa pendidikan di bawah satu tahun hingga lima tahun ke atas.

Google form dipilih sebagai sarana pengumpulan data karena lebih memungkinkan untuk dilakukan selama pandemi covid-19 serta sangat akurat membantu proses klasifikasi data profil dan tanggapan responden yang diterima. Dengan metode pengumpulan data tersebut, jelas bahwa jenis data yang terkumpul adalah data primer berupa profil dan tanggapan responden dalam format google form yang telah didesain khusus untuk pengumpulan data penelitian ini. Setiap item kuesioner diukur dengan skala Likert 5 poin, mulai dari nilai 1 untuk jawaban "sangat tidak setuju" hingga nilai 5 untuk jawaban "sangat setuju". Dalam penelitian ini, seluruh indikator kuesioner diuji validitas dan reliabilitasnya serta terbukti bahwa setiap kelompok indikator untuk setiap varibel valid berdasarkan nilai faktor loading $>0.35$ dan reliabel berdasarkan nilai Cronbach's Alpha $>0.60$.

Untuk pengukuran variabel faktor-faktor profesional, personal, lingkungan, teknologi informasi, penggunaan e-learning berkelanjutan dan prestasi mahasiswa diadaptasi dari Kapot et al. (2020), sedangkan untuk variabel kepuasan dari Chang (2013). Di dalam penelitian ini, faktor-faktor profesional, personal, lingkungan, teknologi informasi dan kepuasan merupakan variabel independen, penggunaan e-learning berkelanjutan sebagai variabel mediasi, dan variabel prestasi mahasiswa sebagai variabel dependen. Faktor-faktor profesional terdiri dari dukungan fakultas, manajemen dan pembelajaran, dengan item pernyataan sebagai berikut :

\section{Dukungan Fakultas}

1. Penting bagi saya untuk menggalakkan penggunaan sistem e-learning di dalam fakultas

2. Penting bagi saya untuk menyediakan sumber daya yang bermanfaat bagi sistem e-learning di fakultas

3. Ketika saya sedang menggunakan sistem e-learning, pemberian bantuan teknis dari fakultas sangat penting

4. Secara umum, fakultas telah mendukung penggunaan e-learning dalam lingkungan pembelajaran.

\section{Dukungan Manajemen}

5. Saya selalu didukung dan didorong oleh dosen saya untuk menggunakan sistem e-learning dalam melakukan pembelajaran saya.

6. Dosen saya sangat tertarik dengan penggunaan sistem e-learning.

7. Saya selalu didukung dan didorong oleh administrator fakultas agar menggunakan sistem $e$ learning untuk meningkatkan kinerja pembelajaran saya. 


\section{Dukungan Pembelajaran}

8. Penugasan pembelajaran dirancang untuk mempromosikan perkembangan pribadi

9. Memperoleh informasi baru tentang cara-cara melakukan pembelajaran dengan lebih efektif adalah hal penting di dalam fakultas.

10. Penugasan pembelajaran meliputi kesempatan untuk mempelajari teknik dan prosedur baru untuk meningkatkan kinerja

Faktor-faktor personal merujuk pada harapan kinerja, keunggulan relatif, kesesuaian, dan sikap; yang diukur melalui item pernyataan sebagai berikut :

\section{Harapan Kinerja}

1. Penggunaan e-learning meningkatkan kinerja dalam pembelajaran saya.

2. Penggunaan e-learning meningkatkan efektivitas dalam kegiatan pembelajaran saya.

3. Penggunaan e-learning dalam kegiatan pembelajaran saya meningkatkan produktivitas.

4. Saya mendapatkan manfaat e-learning untuk kegiatan pembelajaran saya.

\section{Keuntungan Relatif}

5. Penggunaan e-learning akan memudahkan saya dalam melakukan pembelajaran.

6. Penggunaan $e$-learning akan membantu saya untuk menyelesaikan tugas-tugas dengan lebih cepat.

7. Penggunaan e-learning akan meningkatkan kualitas pembelajaran yang saya lakukan.

8. Penggunaan e-learning akan meningkatkan efektivitas saya dalam belajar.

\section{Kesesuaian}

9. Penggunaan e-learning akan sesuai dengan semua aspek pembelajaran saya.

10. Saya berpikir bahwa penggunaan e-learning akan sangat sesuai dengan cara yang saya sukai dalam belajar.

11. Menggunakan e-learning akan sesuai dengan gaya belajar saya.

\section{Sikap}

12. Menggunakan e-learning merupakan ide yang baik.

13. E-learning menyediakan sebuah lingkungan belajar yang menarik.

14. Saya percaya bahwa bekerja dengan sistem e-learning tidak membuat saya stres.

15. Secara keseluruhan, saya suka menggunakan e-learning.

Untuk pengukuran faktor-faktor lingkungan mencakup rekan kuliah, keluarga dan teman, dan dukungan sosial lainnya, melalui item pernyataan sebagai berikut :

\section{Rekan Kuliah}

1. Keyakinan rekan kuliah terhadap e-learning mendorong saya untuk menggunakannya.

2. Pemikiran rekan kuliah mempengaruhi sejauh mana saya menggunakan e-learning.

3. Keyakinan rekan kuliah akan e-learning mengkondisikan saya untuk menggunakannya.

\section{Keluarga dan Teman}

4. Orang yang penting bagi saya berpikir bahwa saya harus berpartisipasi dalam kegiatan pembelajaran berbasis jaringan.

5. Orang yang mempengaruhi perilaku saya berpikir bahwa saya harus berpartisipasi dalam kegiatan e-learning.

6. Manajemen fakultas telah mendukung partisipasi saya dalam kegiatan e-learning. 


\section{Orang Lain}

7. Saya membaca/melihat berita yang menginformasikan bahwa penggunaan sistem e-learning merupakan cara belajar yang baik.

8. Pendapat ahli menggambarkan sentimen positif untuk menggunakan $e$-learning.

9. Laporan media massa meyakinkan saya untuk menggunakan e-learning.

\section{Rekan Kuliah}

10. Keyakinan rekan kuliah terhadap e-learning mendorong saya untuk menggunakannya.

11. Pemikiran rekan kuliah mempengaruhi sejauh mana saya menggunakan e-learning.

12. Keyakinan rekan kuliah akan e-learning mengkondisikan saya untuk menggunakannya.

\section{Keluarga dan Teman}

13. Orang yang penting bagi saya berpikir bahwa saya harus berpartisipasi dalam kegiatan pembelajaran berbasis jaringan.

14. Orang yang mempengaruhi perilaku saya berpikir bahwa saya harus berpartisipasi dalam kegiatan e-learning.

15. Manajemen fakultas telah mendukung partisipasi saya dalam kegiatan e-learning.

\section{Orang Lain (Bhattacherjee (2000), Roca et al. (2006))}

16. Saya membaca/melihat berita yang menginformasikan bahwa penggunaan sistem e-learning merupakan cara belajar yang baik.

17. Pendapat ahli menggambarkan sentimen positif untuk menggunakan $e$-learning.

18. Laporan media massa meyakinkan saya untuk menggunakan e-learning.

Faktor teknologi informasi terkait dengan kemampuan dan kemudahan menggunakan tenologi informasi dalam sistem e-learning tertentu, diukur melalui item pernyataan berikut ini :

1. Mudah bagi saya untuk menjadi terampil dalam menggunakan sistem e-learning.

2. Interaksi saya dengan sistem e-learning jelas dan dapat dipahami.

3. Saya merasa mudah untuk mendapatkan sistem e-learning dalam melakukan apa yang mau saya lakukan.

4. Saya merasa sistem e-learning mudah untuk digunakan.

Pengukuran variabel faktor kepuasan yang berhubungan dengan pengalaman senang menggunakan sistem e-learning menggunakan item pernyataan di bawah ini :

1. Saya puas dengan kinerja sistem e-learning.

2. Saya senang dengan pengalaman menggunakan sistem $e$-learning.

3. Keputusan saya untuk menggunakan sistem e-learning adalah keputusan yang bijaksana.

Variabel penggunaan berkelanjutan merujuk pada niat untuk terus-menerus menggunakan $e$ learning tertentu, diukur dengan menggunakan pernyataan berikut :

1. Saya berniat terus-menerus menggunakan sistem e-learning untuk mengumpulkan pengetahuan.

2. Saya berniat terus-menerus menggunakan sistem e-learning dalam membentuk pengetahuan.

3. Saya berniat terus-menerus menggunakan sistem e-learning untuk berbagi pengetahuan.

4. Secara keseluruhan, saya berniat terus-menerus menggunakan sistem e-learning.

Terakhir, variabel prestasi mahasiswa mengacu pada produktivitas dan efektivitas belajar mahasiswa yang akan terwujud jika secara konsisten menggunakan e-learning tertentu. Variabel ini diukur dengan item pernyataan : 
1. Penggunaan e-learning memperbaiki prestasi belajar saya.

2. Penggunaan $e$-learning meningkatkan produktivitas belajar saya.

3. Penggunaan e-learning menambah efektivitas belajar saya.

4. Secara keseluruhan, e-learning berguna dalam mengelola pembelajaran saya.

Isian data responden didesain dalam google form sebagai jenis pertanyaan yang wajib diisi oleh responden. Hal ini sangat menjamin validitas dan reliabilitas data yang terkumpul karena dapat dipastikan tidak ada satu kuesioner pun yang tidak diisi oleh responden. Selanjutnya, data yang terkumpul dianalisis dengan analisis statistik deskriptif dan pengujian hipotesis dengan menggunakan model Structural Equation Modeling (SEM). Tingkat signifikansi untuk pengujian hipotesis dalam penelitian ini sebesar 0,05 ( $\alpha$ 5\%).

\section{HASIL DAN PEMBAHASAN}

\section{Pengujian Hipotesis dan Pembahasan Hasil}

Hasil pengujian hipotesis penelitian ini tampak dalam tabel berikut ini.

Tabel 1. Hasil pengujian hipotesis

Sumber Tabel: Hasil kuesioner diolah dengan AMOS 22.0 (2020)

\begin{tabular}{lccc}
\hline \multicolumn{1}{c}{ Hipotesis } & Koefisien & Prob & Kesimpulan \\
\hline $\begin{array}{l}\text { H1: Terdapat pengaruh positif faktor-faktor profesional terhadap } \\
\text { penggunaan } \text {-learning berkelanjutan. }\end{array}$ & $-0,299$ & 0,174 & H1 ditolak \\
H2: Terdapat pengaruh positif faktor-faktor personal terhadap & 0,735 & 0,000 & H2 diterima \\
$\quad \begin{array}{l}\text { penggunaan } \text {-learning berkelanjutan } \\
\text { H3: Terdapat pengaruh positif faktor-faktor lingkungan terhadap } \\
\text { penggunaan e-learning berkelanjutan. }\end{array}$ & 0,336 & 0,130 & H3 ditolak \\
$\begin{array}{l}\text { H4: Terdapat pengaruh positif faktor-faktor teknologi terhadap } \\
\text { penggunaan } \text {-learning berkelanjutan. }\end{array}$ & 0,071 & 0,690 & H4 ditolak \\
$\begin{array}{l}\text { H5: Terdapat pengaruh positif kepuasan dalam menggunakan } e- \\
\text { learning terhadap penggunaan } \text {-learning berkelanjutan. }\end{array}$ & 0,043 & 0,882 & H5 ditolak \\
H6: Terdapat pengaruh positif penggunaan -learning berkelanjutan & 0,770 & 0,000 & H6 diterima
\end{tabular}

terhadap prestasi mahasiswa.

Dari tabel di atas, terbukti ada dua hipotesis yang diterima, yaitu (H2): “Terdapat pengaruh positif faktor-faktor personal terhadap penggunaan e-learning berkelanjutan" dengan nilai koefisien sebesar 0,735 dan (H6): "Terdapat pengaruh positif penggunaan e-learning berkelanjutan terhadap prestasi mahasiswa" dengan nilai koefisiennya sebesar 0,770 . Hanya kedua hipotesis ini yang diterima karena $p$-value atau probabilitas kekeliruannya lebih kecil dari nilai tingkat signifikansi $0,05(\alpha 5 \%)$, yaitu sebesar 0,000 . Hasil ini mengafirmasi penelitian-penelitian sebelumnya bahwa faktor-faktor personal merupakan determinan yang sangat signifikan mempengaruhi peserta didik untuk menggunakan e-learning secara berkelanjutan (Venkatesh et al., 2003; Pynoo et al., 2011; Venkatesh et al., 2012; Kapo et al., 2020; Taiwo and Downe, 2013; Al-Harbi, 2011), dan jika secara konsisten e-learning digunakan berkelanjutan, peserta didik akan berprestasi (Bhattacherejee, 2001; Bhattacherejee and Barfar, 2011; Oye et al., 2011; Yilmaz et al., 2013; Elfaki et al., 2019; Suryaman et al., 2020; Abumandour, 2020; Dhawan, 2020; Hossain et al., 2020).

Selain H2 dan H6, hasil pengujian hipotesis membuktikan bahwa H1, H3, H4, dan H5 ditolak. Penolakan terhadap H5 lebih tinggi karena memiliki nilai $p$-value yang paling besar, yaitu 0,882 , lalu menyusul penolakan terhadap $\mathrm{H} 4, \mathrm{H} 1$ dan $\mathrm{H} 3$. Hal ini bisa dipahami dengan adanya pandemi covid-19 sebagai pemicu ketidakpuasan (H5) terhadap desain teknologi informsi (H4) yang masih berpusat pada para pengajar (H1) dan lingkungan (H3) pembelajaran. Hadirnya covid-19 dirasa 
seperti sebuah benda asing yang jatuh menabrak bumi secara tiba-tiba dan memberi dentuman besar yang mengagetkan, sehingga hampir semua elemen di dunia pendidikan belum siap untuk sebuah sistem pembelajaran yang semata-mata hanya berbasis elektronik (e-learning). Penghentian kuliah tatap muka langsung di kelas tanpa direncanakan pun terjadi di mana-mana (Tsekea and Chigwada, 2020). Di Indonesia pun terjadi hal yang sama (Fatoni et al., 2020). Solusi yang urgen dilakukan adalah pembelajaran hanya boleh dilakukan secara online (Almekhlafy, 2020). Akan tetapi, sistemnya masih berpusat pada pihak fakultas/universitas, manajemen, dan pengajar. Oleh karena itu, "wajar" bila sebagian besar peserta didik tidak puas dengan sistem $e$ learning yang belum disiapkan dengan baik, sehingga dirasakan perlu adanya pembaruan sistem pembelajaran di era normal baru ini.

Yang menarik dalam penelitian ini adalah nilai koefisien dari variabel faktor-faktor profesional sebesar -0,299 (nilainya negatif); artinya semakin tinggi pengaruh faktor-faktor profesional, justru akan semakin rendah niat peserta didik untuk menggunakan e-learning secara berkelanjutan. Dengan kata lain, jika pemusatan pembelajaran di era normal baru ini lebih ditekankan pada faktorfaktor profesional, maka akan timbul efek negatif pada penggunaan e-learning berkelanjutan. Selain itu, hasil pengujian ini juga menunjukkan bahwa nilai $p$-value lebih besar dari tingkat signifikansi penelitian ini, yaitu 0,174>0,05 ( $\alpha$ 5\%). Oleh karena itu, dapat disimpulkan secara statistik pada tingkat kepercayaan $95 \%$ bahwa hipotesis ini ditolak. Hal ini membuktikan secara empiris kebenaran pendekatan heutagogi yang menekankan bahwa untuk mencapai prestasi mahasiswa melalui penggunaan e-learning berkelanjutan, determinan utamanya adalah diri peserta didik itu sendiri (Blaschke and Hase, 2016), bukan faktor-faktor profesional. Dalam hal ini, sistem pembelajaran yang ditentukan oleh diri sendiri (self-determined learning) merupakan unsur terpenting. Jadi, penekanan berlebihan pada faktor-faktor profesional yang cenderung untuk menempatkan pihak fakultas, manajemen, kurikulum rancangan lembaga pendidikan dan pengajar sebagai pusat pembelajaran harus ditinggalkan (Knowles, 1980; Hase and Kenyon, 2000; Blaschke 2012; Blaschke and Hase, 2016).

Kata heutagogi sangat dekat artinya dengan kata Yunani heuriskein, yaitu sebuah metode pengajaran yang memungkinkan peserta didik untuk menyingkapkan sendiri (Nikolovska et al., 2020). Berhadapan dengan pandemi covid-19, pendekatan heutagogi atau pembelajaran yang ditentukan oleh diri sendiri merupakan solusi yang relevan dan aktual di dunia pendidikan. Heutagogi merupakan pendekatan yang mendorong peserta didik untuk menjadi partisipan yang aktif dalam apa yang sedang dipelajarinya (Nikolovska et al., 2020). Dengan pendekatan ini, peserta didik dapat menggunakan e-learning secara berkelanjutan sehingga berprestasi.

\section{Deskripsi Statistik}

Penelitian ini menggunakan SEM untuk menganalisis faktor konfimatori, analisis jalur dan analisis regeresi atau model struktural (Indartono, 2017). Analisis konfirmatori dalam penelitian ini bertujuan untuk menguji validitas dan reliabilitas instrumen, analisis jalur untuk menguji hubungan antar variabel, dan analisis regresi atau model struktural bertujuan untuk mendapatkan suatu model yang cocok untuk prediksi (Sugiyono, 2017). Ketiga analisis tersebut diuraikan sebagai berikut.

Dalam penelitian ini, jumlah responden yang mengisi kuesioner (50 pernyataan) sebanyak 279 responden. Tidak ada item kuesioner yang tidak diisi oleh responden. Hasil uji kualitas data pada setiap dimensi untuk setiap variabel terbukti bahwa semuanya valid berdasarkan nilai faktor loading $>0.35$ dan reliabel berdasarkan nilai Cronbach's Alpha $>0.60$. Dengan kata lain, terdapat konsistensi internal dalam pernyataan-pernyataan kuesioner setiap variabel sehingga dapat 
membentuk konstruk dari setiap variabel. Jadi, hasil analisis konfirmatori penelitian ini menyatakan valid dan reliabel terhadap semua item kuesioner dari setiap variabel sebagai satu kesatuan konstruk alat ukur penelitian ini.

Berdasarkan analisis jalur, diperoleh hasil bahwa ada hubungan antarvariabel di antara semua variabel. Hal ini tampak dalam deskripsi statistik penelitian ini berupa nilai maksimum, minimum, rata-rata dan standar deviasi (Sekaran and Bougie, 2016). Hasil analisis statistik deskriptif menyatakan bahwa nilai minimum tanggapan responden sebesar 1 (sangat tidak setuju) dan maksimumnya 5 (sangat setuju). Nilai rata-rata tanggapan responden untuk setiap item kuesioner berkisar antara 3 (cukup setuju) dan 4 (setuju). Besaran standar deviasinya berkisar di antara angka 0 dan 1 (Sekaran and Bougie, 2016). Data selengkapnya tertera pada Tabel 1 berikut ini.

Tabel 2. Hasil analisis tanggapan responden

Sumber Tabel: Hasil kuesioner diolah dengan AMOS 22.0

\begin{tabular}{lccccc}
\hline \multicolumn{1}{c}{ Variabel } & N & Minimum & Maksimum & Rata-rata & Standar Deviasi \\
\hline PROFESIONAL & 279 & 2,50 & 5,00 & 4,2019 &, 53901 \\
PERSONAL & 279 & 1,00 & 5,00 & 3,8442 &, 81933 \\
LINGKUNGAN & 279 & 1,33 & 5,00 & 3,9024 &, 73600 \\
TI & 279 & 1,00 & 5,00 & 3,9615 &, 73400 \\
KEPUASAN & 279 & 1,00 & 5,00 & 3,8244 &, 83046 \\
PB & 279 & 1,00 & 5,00 & 3,7384 &, 96387 \\
PM & 279 & 1,00 & 5,00 & 3,6595 &, 97570 \\
Valid N (listwise) & 279 & & & &
\end{tabular}

Tabel hasil analisis jalur terhadap tanggapan responden ini menunjukkan bahwa sebaran nilai jawaban responden merata untuk setiap item kuesioner dan tidak terdapat penyimpangan yang besar.

\section{KESIMPULAN DAN SARAN}

Berdasarkan hasil penelitian di atas, dapat disimpulkan bahwa penggunaan e-learning berkelanjutan dengan tujuan untuk meningkatkan prestasi mahasiswa sangat ditentukan oleh faktor-faktor personal setiap mahasiswa. Fakor-faktor selain faktor personal tidak berpengaruh signifikan bahkan bisa kontraproduktif terhadap prestasi mahasiswa.

Implikasinya, sangatlah urgen agar setiap elemen pada setiap level di dalam lembaga pendidikan formal memberikan perhatian serius pada faktor-faktor personal, meliputi perhatian pada harapan prestasi mahasiswa, keunggulan relatif yang diharapkan mahasiswa, kesesuaian mahasiswa dengan sistem e-learning yang dipilih di dalam sebuah lembaga pendidikan formal, dan sikap mahasiswa yang bersedia menerima dan secara berkelanjutan menggunakan e-learning. Dengan demikian, peserta didik akan konsisten dalam menggunakan e-learning sehingga prestasi mahasiswa yang menjadi cita-cita utama setiap universitas bisa tercapai. Keterbatasan penelitian ini adalah tidak memberikan pemahaman (Koehler and Mishra, 2013; Salim et al., 2020) terlebih dahulu kepada responden mengenai cakupan makna e-learning berkelanjutan, konsekuensinya responden mereduksinya hanya pada sarana pembelajaran daring selama pandemi covid-19. Oleh karena itu, saran kami adalah perlu diberikan literasi mengenai e-learning berkelanjutan sebelum melakukan penelitian lanjutan tema ini, bahkan jika dipandang perlu bisa dimasukkan juga sebagai salah satu variabel pada penelitian-penelitian selanjutnya.

\section{Ucapan Terima Kasih}

Penulis mengucapkan terima kasih berlimpah kepada Panitia Konferensi Nasional Riset Manajemen (KNRM) XI yang telah menyelenggarakan konferensi ini sehingga memberi 
kesempatan untuk melakukan penelitian dan mempresentasikan hasil penelitian ini pada tanggal 17-18 Februari 2021, juga telah menghubungkan penulis dengan Jurnal Muara Ilmu Ekonomi dan Bisnis (JMIEB) Universitas Tarumanegara.

\section{REFERENSI}

Abumandour, E. T. (2020). Public Libraries' Role in Supporting E-learning and Spreading Lifelong Education: A Case Study. Journal of Research in Innovative Teaching \& Learning. Retrieved October 12, 2020, from https://www.emerald.com/insight/23977604.htm.

Achour, M., Khalil, S. B. A., Ahmad, B. B., Nor, M. R. M., \& Yusoff, M. Y. Z. B. M. (2017). Management and Supervisory Support as A Moderator of Work-family Demands and Women's Well-being. $\quad$ Humanomics, 33(3): 335-356. https://econpapers.repec.org/article/emehumpps/h-02-2017-0024.htm

Alam, A. \& Ahmad, M. (2018). The Role of Teachers' Emotional Intelligence in Enhancing Student Achievemet. Journal of Asia Business Studies, 12(1): 31-43. https://doi.org/10.1108/JABS-08-2015-0134

Al-Harbi, K. A. (2011). E-learning in the Saudi Tertiary Education: Potential and Challenges. Applied Computing and Informatics, 9: 31-46.https://doi.org/10-1016/j.aci.2010.03.002

Almekhlafy, S. S. A. (2020). Online Learning of English Language Course via Blackboard at Saudi Universities in the Era of COVID-19: Perception and Use. PSU Research Review. Retrieved November 16, 2020, from http://creativecommons.org/licences/by/4.0/legalcode.

Blaschke, L. M. (2012). Heutagogy and Lifelong Learning: A Review of Heutagogical Practice and Self-Determined Learning. The International Review of Research in Open and Distance Learning, 13 (1): 56-71. https://doi.org/10.19173/irrodl.v13i1.1078

Blaschke, L. M. \& Hase, S. (2016). Heutagogy: A Holistic Framework for Creating TwentyFirst-Century Self-determined Learners, dalam Gros, B., Kinshuk dan Maina, M. (Eds). The Future Ubiquitous Learning, Learning Designs for Emerging Pedagogies, Lecture Notes in Educational Technology, Berlin Heidelberg: Springer-Verlag.

Boros, S. \& van Gorp, L. (2017). Networks in Professional Groups: A Matter of Connection or Self-exile? Team Performance Management: An International Journal, 23(7/8): 318332.https://doi.org/10.1108/TPM-10-2016-0044

Dhawan, S. (2020). Online Learning: A Panacea in the Time of COVID-19 Crisis. Journal of Educational Technology, 49(1): 5-22. https://doi.org/10.1177/0047239520934018

Diño, M. J. S. \& de Guzman, A. B. (2015). Using Partial Least Squares (PLS) in Predicting Behavioral Intention for Telehealth Use among Filipino Elderly. Educational Gerontology, 41(1): 53-68. https://doi.org/10.1080/03601277.2014.917236

Doucet, A., Netolicky, D., Timmers, K., \& Tuscano, F. J. (2020). Thinking about Pedagogy in an Unfolding Pandemic: An Independent Report on Approaches to Distance Learning During COVID-19 School Closures, 29 Maret. Retrieved December 20, 2020, from https://issuu.com/educationinternational/docs/2020_research_covid-19_eng

Elfaki, N. K., Abdulraheem, I., \& Abdulrahim, R. (2019). Impact of E-learning Vs Traditional Learning on Students' Performance and Attitude. International Medical Journal, 24 (3): 225-233. https://www.researchgate.net/publication/338528127_Impact_of_elearning_vs_traditional_learning_on_students'_performance_and_attitude

Fatoni, Arifiati, N., Nurkhayaati, E., Nurdiawati, E., Fidziah, Pamungkas, G., Adha, S., Irawan, Purwanto, A., Julyanto, O., \& Azizi, E. (2020). University Student Online Learning System during Covid-19 Pandemic: Advantages, Constraints and Solutions. Systematic Reviews in Pharmacy, 11(7): 570-576. https://www.sysrevpharm.org/articles/university- 
students-online-learning-system-during-covid19-pandemic-advantages-constraints-andsolutions.pdf

Foroughi, B., Iranmanesh, M., \& Hyun, S. S. (2019). Understanding the Determinants of Mobile Banking Continuance Usage Intention. Journal of Enterprise Information Management, 32(6): 1015-1033. https://doi.org/10.1108/JEIM-10-2018-0237

Hase \& Kenyon. (2001). From Andragogy to Heutagogy. Original ultiBASE publication. Retrieved November 15, 2020, from http://ultibase.rmit.edu.au/Articles/dec00/hase2.htm.

Hernandez, B., Montaner, T., Sese, F. J., \& Urquizu, P. (2011). The Role of Social Motivations in E-learning: How Do They Affect Usage and Success of ICT Interactive Tools? Computers in Human Behavior, 27: 2224-2232. https://doi.org/10.1016/j.chb.2011.07.001

Hsu, H., Liu, F., Tsou, H., \& Chen, L. (2019). Openness of Technology Adoption, Top Management Support and Service Innovation: A Social Innovation Perspective. Journal of Business \& Industrial Marketing, 34(2): 575-590. https://doi.org/10.1108/JBIM-03-20170068

Indartono, S. I. (2017). Metodologi Riset SDM. Yogyakarta: UNY Press.

Ja'ashan, M. M. N. H. (2015). Perceptions and Attitudes towards Blended Learning for Englihs Courses: A Case Study of Students at University of Bisha. Canadian Center of Science and Education, 8(9): 40-50. http://doi.org/10.5539/elt.v8n9p40

Kapo, A., Mujkic, A., Turulja, L., \& Kovačević, J. (2020). Continuous E-learning at the Workplace: The Passport for Future of Knowledge. Information Technology \& People. Retrieved October 14, 2020, from https://www.emerald.com/insight/0959-3845.htm

Kheruniah, A. E. (2013). A Teacher Personality Competence Contribution to A Student Study Motivation and Discipline to Fiqh Lesson. International Journal of Scientific \& Technology Research, 2(2): 108-112. https://www.ijstr.org/paperreferences.php?ref=IJSTR-0213-5760

Knowles, M. S. (1980). The Modern Practice of Adult Education, From Pedagogy to Andragogy. New York: Cambridge.

Koehler, M. J. \& Mishra, P. (2009). What is Technological Pedagogical Content Knowledge? Contemporary Issues in Technology and Teacher Education, 9(1): 60-70.

Lai, H. \& Chen, C. (2011). Factors Influencing Secondary School Teachers' Adoption of Teaching Blogs. Computers \& Education, 56: 948-960. https://doi.org/10.1016/j.compedu.2010.11.010

Lee, M. (2010). Explaining and Predicting Users' Continuance Intention toward E-learning: An Extension of the Expectation-confirmation Model. Computers \& Education, 54: 506-516. https://doi.org/10.1016/j.compedu.2009.09.002

Levin, R. I., \& Rubin, D. S. (1991). Statistics for Management. New Jersey: Prentice-Hall.

Lind, D. A., Marchal, W. G., \& Wathen, S. A. (2014). Teknik-teknik Statistika dalam Bisnis dan Ekonomi (15 ed.). (R. B. Hartarto, Trans.) Jakarta: Salemba Empat.

Liu, M. \& Liu, C. (2020). The Adoption of E-learning Beyond MOOCs for Higher Education. International Journal of Accounting \& Information Management. Retrieved November 16, 2020, from https://www.emerald.com/insight/1834-7649.htm .

Moradi, M., Tarighi, H., Hosseinipour, R., \& Saravani, M. (2020). Factors Influencing the Learning of Accounting Information System (AIS), Evidence from Iranian Students. Journal of Economic and Administrative Sciences, 36(3): 226-245. https://doi.org/10.1108/JEAS-02-2019-0014

Moawad, R. A. (2020). Online Learning during the COVID-19 Pandemic and Academic Stress in University Students. Revista Romaneasca pentru Educatie Multidimensionala, 12(1/2), Retrieved October 5, 2020 from https://doi.org/10.18662/rrem/12.1sup1/ 
Nikolovska, A. I., Grizev, A., \& Iliev, A. (2020). History of Heutagogy as A Self-determinated Learning. 2nd International Scientific Conference MILCON'19, Skopje. Retrieved November 16, 2020, from https://www.researchgate.net/publication/340413627

Oye, N.D., Salleh, M., \& Iahad, N. A. (2011). Challenges of E-learning in Negerian University Education Based on the Experience of Developed Countries. International Journal of Managing Information Technology, 3(2): 39-48. http://dx.doi.org/10.5121/ijmit.2011.3204

Pynoo, B., Devolder, P., Tondeur, J., van Braak, J., Duyck, W., \& Duyck, P. (2011). Predicting Secondary School Teachers' Acceptance and Use of a Digital Learning Environment: A Cross-sectional Study. Computers in Human Behavior, 27(1): 568-575. http://doi.org/10.1016/j.chb.2010.10.005

Rogers, E. M. (1983). Diffusion of Innovations (3 ed.). New York: Free Press.

Sekaran, U. (2003). Research Methods for Business, A Skill-Building Approach (4 ed.). USA: John Wiley \& Sons.

Sekaran, U., \& Bougie, R. (2016). Research Methods for Business, A Skill-Building Approach (7 ed.). UK: John Wiley \& Sons.

Shehzadi, S., Nisar, Q. A., Hussain, M. S., Basheer, M. F., Hameed, W. U., \& Chaudhry, N. I. (2020). The Role of Digital Learning toward Student's Satisfaction and University Brand Image at Education Institutes of Pakistan: A Post-effect of COVID-19. Asian Education and Development Sutdies. Retrieved Desember 10, 2020, from https://www.emerald.com/insight/2046-3162.htm

Shi, L., Yao, X., \& Wu, W. (2020). Perceived University Support, Entrepreneurial Self-efficacy, Heterogeneous Entrepreneurial Intentions in Entrepreneurship Education, the Moderating Role of the Chinese Sense of Face. Journal of Entrepreneurship in Emerging Economics, 12(2): 205-230. https://doi.org/10.1108/JEEE-04-2019-0040

Sidratulmunthah, Hussain, S., \& Malik, M. I. (2018). Towards Nurturing the Entrepreneurial Intentions of Neglected Female Business Students of Pakistan through Proactive Personality, Self-Efficacy and University Support Factors. Asia Pasific Journal of Innovation and Entrepreneurship, 12(3): 363-378. https://doi.org/10.1108/APJIE-03-20180015

Sugiyono. (2017). Statistika untuk Penelitian. Bandung: Alfabeta.

Suryaman, M., Cahyono, Y., Mulansyah, D., Bustani, O., Suryani, P., Fahlevi, M., Pramono, R., Purwanto, A., Purba, J. T., Munthe, A. P., Juliana., \& Harimurti, S. M. (2020). Covid-19 Pandemic and Home Online Learning System: Does It Affect the Quality of Pharmacy School Learning? Systematic Reviews in Pharmacy, 11(8): 524-530. https://search.bvsalud.org/global-literature-on-novel-coronavirus-2019ncov/resource/en/covidwho-846299

Taiwo, A. A. \& Downe, A. G. (2013). The Theory of User Acceptance and Use of Technology (UTAUT): A Meta-analytic Review of Empirical Findings. Journal of Theoretical and Applied Information Technology, 49(1): 48-58.

Tayyaba, S. (2012). Rural-urban Gaps in Academic Achievement, Schooling Conditions, Student, and Teachers' Characteristics in Pakistan. International Journal of Educational Management, 26(1): 6-26. https://doi.org/10.1108/09513541211194356

Trivedi, R. (2016). Does University Play Significant Role in Shaping Entrepreneurial Intention? A Cross-country Comparative Analysis. Journal of Small Business and Enterprise Development, 23(3): 790-811. https://doi.org/10.1108/JSBED-10-2015-0149

Tsekea, S. \& Chigwada, J. P. (2020). COVID-19: Strategies for Positioning the University Library in Support of E-learning. Digital Library Perspective. Retrieved October 16, 2020, from https://www.emerald.com/insight/2059-5816.htm 
Tosuntaş, Ş. B., Karadağ, E., \& Orhan, S. (2015). The Factors Affecting Acceptance and Use of Interactive Whiteboard within the Scope of FATIH Project: A Structural Equation Model Based on the Unified Theory of Acceptance and Use of Technology. Computers \& Education, 81: 167-178. https://www.journals.elsevier.com/computers-and-education

Venkatesh, V., Morris, M. G., Davis, G. B., \& Davis, F. D. (2003). User Acceptance of Information Technology: Toward a Unified View. MIS Quarterly, 27(3): 425-478. https://doi.org/10.2307/30036540

Venkatesh, V., Thong, J. Y. L., \& Xu, X. (2012). Consumer Acceptance and Use of Information Technology: Extending the Unified Theory of Acceptance and Use of Technology. MIS Quarterly, 36(1): 157-178. https://papers.ssrn.com/sol3/papers.cfm?abstract_id=2002388

Yilmaz, B., Külcu, Ö., Ünal, Y., \& Çakmak, T. (2013). Distance Education on Digitalization: Evaluation of An Application in Turkey. Aslib Proceedings: New Information Perspectives, 65(4): 336-357). http://doi.org/10.1108/AP-11-2011-0049

Zainuddin, Z., Parera, C. J., Haruna, H., \& Habiburrahim, H. (2020). Literacy in the New Norm: Stay-home Game Plan for Parents. Information and Learning Sciences, 121(7/8): 645-653. https://doi.org/10.1108/ILS-04-2020-0069

Zuiderwijk, A., Janssen, M., \& Dwivedi, Y. K. (2015). Acceptance and Use Predictors of Open Data Technologies: Drawing upon the Unified Theory of Acceptance and Use of Technology. Government Information Quarterly, 32: 429-440. https://doi.org/10.1016/j.giq.2015.09.005 